\title{
Engineering History and Heritage: Referees 2019
}

The following is a list of referees who have reviewed papers for Engineering History and Heritage between 1 December 2018 and 30 November 2019. The Institution of Civil Engineers is very grateful for their assistance.

We are continually looking for suitable reviewers for papers submitted to Engineering History and Heritage. Papers published in the Proceedings of the ICE must be submitted to at least two independent referees to judge accuracy, style, impact, importance and interest.

If you are interested in reviewing articles on any topic related to engineering history and heritage, please submit your name, qualifications or CV, and

Timothy Abbott

William Addis

Richard Bailey

Michael Bartlett

Alasdair Beal

Keith Bowers

Jorge Branco

David Broadbent

David Brown
Rene Brueckner

Murude Celikag

Ann Coats

John Collins

Dennis De Witt

Ayanangshu Dey

Hamish Douglas

Stephen Fernandez

Donald Friedman

areas of expertise. We are in need of individuals who will agree to review papers in a timely fashion (within 3 to 4 weeks of receipt) and provide confidential feedback to the Editorial Advisory Panel concerning the quality of the paper and any suggested revisions that would be appropriate.

If you are such a person, please contact Rebecca Rivers (tel.: +44 (0)207 665 2241; e-mail: rebecca.rivers@icepublishing.uk) for more information on the referee process.

David Greenfield

William Hamilton

Mohammad Amin Hariri-Ardebili

Bill Harvey

Lawrence Hurst

lan Jenkinson

Stephen Jones

Deborah Lazarus

Maria Lippiello
Jennifer Murgatroyd

David Nethercot

Eberhard Pelke

David Perrett

Susan Ross

Scott Steedman

Dimitris Theodossopoulos

Mark Watson

Mark Wheel 